\title{
Editorial: The Role of Teachers in Students' Social Inclusion in the Classroom
}

\author{
Luciano Gasser ${ }^{1 *}$, Antonius H. N. Cillessen ${ }^{2}$, Christian Huber ${ }^{3}$, Tim Mainhard ${ }^{4}$, \\ Christoph Michael Müller ${ }^{5}$ and Carmen L. A. Zurbriggen ${ }^{6}$ \\ 1 Institute of Research, Development and Evaluation, Bern University of Teacher Education, Bern, Switzerland, ${ }^{2}$ Behavioural \\ Science Institute, Radboud University, Nijmegen, Netherlands, ${ }^{3}$ School of Education, University of Wuppertal, Wuppertal, \\ Germany, ${ }^{4}$ Education and Child Studies, Leiden University, Leiden, Netherlands, ${ }^{5}$ Department of Special Education, \\ University of Fribourg, Fribourg, Switzerland, ${ }^{6}$ Department of Social Sciences, University of Luxembourg, Esch-sur-Alzette, \\ Luxembourg
}

Keywords: peer relationships, teacher behaviors, student-teacher relationships, friendships, peer acceptance, bullying, social reference theory, special educational needs

\section{Editorial on the Research Topic}

\section{The Role of Teachers in Students' Social Inclusion in the Classroom}

Students' social inclusion has serious implications for their social, emotional and academic adjustment (Ladd and Troop-Gordon, 2003; Sette et al., 2020). The current Research Topic conceptualizes social inclusion from a contextual perspective and not merely as the result of students' individual social competences. From this perspective, teachers represent an important element in the classroom social ecology significantly contributing to peer group dynamics and thereby also to individual students' social inclusion (Farmer et al., 2011; Juvonen et al., 2019). Based on attachment theory, some researchers have argued that teacher behaviors expressing warmth, sensitivity and responsiveness contribute to students' safe exploration of their peer worlds (Sabol and Pianta, 2012; Verschueren and Koomen, 2012; Roorda et al., 2021). Other researchers have highlighted the importance of teachers' feedback toward individual students because they act as social referrers that communicate evaluative information about the likability of individual students (Hendrickx et al., 2017; Huber et al., 2018). However, despite an increasing interest in the role of teachers in peer relationships, we still know relatively little about the multiple avenues along which teachers affect their students' social inclusion.

The current Research Topic substantially contributes to this research gap. It includes fourteen articles that focus on different aspects of children's social inclusion in the classroom (e.g., social acceptance, friendships, victimization, marginalization). These articles cover a broad spectrum of teacher practices (e.g., grouping strategies, behavior management) at different levels of the classroom (the group vs. dyadic relations). Several of the included studies applied a longitudinal design (e.g., Chen et al.; Kim et al.), included relatively large samples (e.g., Furrer et al.; Klang et al.), and used observational methods to assess teacher behaviors (e.g., Garrote et al.; Hendrickx et al.). Moreover, the Research Topic also includes studies that highlight students' and teachers' social-cognitive processing of teachers' influence on social inclusion (e.g., Demol et al.; Mulvey et al.). Finally, some of the studies addressed teacher professional development and interventions to improve students' social inclusion (Farmer et al.). This summary classifies the articles into the following four groups. 


\section{TEACHERS' BEHAVIORS AT THE CLASSROOM LEVEL}

Classroom-level practices refer to the behaviors that teachers show toward the whole group of students instead of individual students. Two studies focused on teacher behaviors in the domain of classroom organization. Garrote et al. used a longitudinal design to study how teachers' inclusive attitudes and observed classroom management (i.e., clear expectations, efficient use of instructional time) predicted children's social acceptance. Classroom management was significantly related to children's social acceptance, suggesting that behavioral measures might be more closely related to students' social inclusion than to affective-motivational teacher characteristics. Kim et al. longitudinally studied the effects of teachers' self-reported grouping strategies on students' friendships and conflicts (e.g., managing behavior problems, heterogeneous ability grouping). Heterogeneous ability grouping negatively predicted children's friendships. The authors explained this finding by children's tendency to form their friendships based on similarity.

Two additional studies addressed teachers' behaviors in the domain of emotional support. Furrer et al. investigated how physical education teachers' support for cooperative skills and individual reference norm orientation (e.g., praising all students for individual improvements) related to the social acceptance of students with and without intellectual disabilities. While teachers' support of cooperative skills positively contributed to the social acceptance of all children, individual reference norm orientation strategies showed stronger effects in children with intellectual disabilities. Finally, Owens et al. showed that the teacher practice of spending individual time with students positively affected students' later social acceptance and academic functioning. Moreover, they found that teachers' behaviors were differentially related to social acceptance of students with and without ADHD.

\section{TEACHERS' BEHAVIORS AT THE DYADIC LEVEL}

Three studies focused on teacher's behaviors toward specific students. The longitudinal study of Hendrickx et al. found that teachers rarely interacted with socially marginalized students. However, consistent with social referencing theory, positive teacher feedback toward socially marginalized and rejected students predicted increases in these students' social acceptance over time. Chen et al. showed that the quality of dyadic relationships with individual students (closeness and conflict) longitudinally predicted younger children's perceptions of peer support and victimization. The study further revealed significant effects of teachers' behavior management on children's perceived victimization. The quality of student-teacher relationships not only enhanced students' social inclusion, but also reduced ingroup bias. Grütter et al. used network analyses to show that students were more likely to prefer peers from different ethnic groups when they perceived their teachers as caring. In contrast, less teacher care was significantly related to ingroup bias. The positive effect of teacher care was even larger in classrooms with strong ethnic group boundaries.

\section{TEACHERS' AND STUDENTS' THINKING ABOUT SOCIAL INCLUSION}

Four studies in this Research Topic investigated social-cognitive processes underlying the role of teachers in students social inclusion, mainly by using hypothetical scenarios on social inclusion or exclusion.

Demol et al. presented children hypothetical scenarios that described either absent teacher intervention to bullying or active teacher interventions (i.e., comforting the victim or correcting the bully). Children expected more antibullying teacher attitudes and more positive bystander interventions from peers and self if teachers actively intervened. Mulvey et al. further showed that students evaluated bystander behaviors such as defending more positively if they perceived the school climate as supportive. Beissert et al. studied pre-service teachers' social cognitions about hypothetical intergroup exclusion. They found that teachers were more likely to condemn exclusion and to intervene if the scenario described interethnic compared to same-ethnic exclusion. Finally, Wilbert et al. argued that teachers' knowledge of their students' social inclusion in the classroom provides them with important diagnostic information for effective individualized interventions. They showed that teachers were moderately accurate in their ratings of their students' social acceptance and rejection. This study also revealed high individual variability in teachers' rating accuracy.

\section{INTERVENTIONS AIMED AT IMPROVING STUDENTS' SOCIAL INCLUSION}

Three articles addressed intervention programs to improve students' social inclusion. Farmer et al. provided an overview of their intervention program "Behavior, Academic and Social Engagement" (BASE). BASE starts with systematic data collection of students' social functioning to determine the specific needs of classrooms. Based on these assessments, teachers join professional development activities that are responsive to students' specific social difficulties (e.g., passive or popular-aggressive students). Klang et al. highlighted the potential of a cooperative learning format for an integrated approach to promote both academic and social learning. Their intervention study provided weak support for the effectiveness of such a format on students' friendships and social acceptance. The researchers recommended more attention to implementation quality of cooperative learning interventions. In a case study, Kraatz et al. compared the teachers' role in high and low effective collaborative discussion groups that were part of a dialogic intervention study (Collaborative Social Reasoning). Their results illustrated the dynamic interplay between teachers' scaffolding and peer group dynamics. Moreover, the cognitive depth of student talk strongly depended on teachers' success in managing challenging group dynamics. 
Collectively, the 14 papers of this Research Topic substantially contribute to our understanding of the role of teachers in students' social inclusion in the classroom. We would like to thank all authors for their contributions and hope that the presented findings will inspire future research in this field.

\section{REFERENCES}

Farmer, T. W., Lines, M. M., and Hamm, J. V. (2011). Revealing the invisible hand: The role of teachers in children's peer experiences. J. Appl. Dev. Psychol. 32, 247-256. doi: 10.1016/j.appdev.2011.04.006

Hendrickx, M. M. H. G., Mainhard, T., Oudman, S., Boor-Klip, H. J., and Brekelmans, M. (2017). Teacher behavior and peer liking and disliking: The teacher as a social referent for peer status. J. Educ. Psychol. 109, 546-558. doi: 10.1037/edu0000157

Huber, C., Gerullis, A., Gebhardt, M., and Schwab, S. (2018). The impact of social referencing on social acceptance of children with disabilities and migrant background: An experimental study in primary school settings. Eur. J. Spec. Needs Educ. 33, 269-285. doi: 10.1080/08856257.2018.1424778

Juvonen, J., Lessard, L. M., Rastogi, R., Schacter, H. L., and Smith, D. S. (2019). Promoting social inclusion in educational settings: Challenges and opportunities. Edu. Psych. 54, 250-270. doi: 10.1080/00461520.2019.1655645

Ladd, G. W., and Troop-Gordon, W. (2003). The role of chronic peer difficulties in the development of children's psychological adjustment problems. Child Dev. 74, 1344-1367. doi: 10.1111/1467-8624.00611

Roorda, D. L., Zee, M., and Koomen, H. M. Y. (2021). Don't forget student-teacher dependency! A meta-analysis on associations with students' school adjustment and the moderating role of student and teacher characteristics. Attach Hum Dev. 23, 490-503. doi: 10.1080/14616734.2020.1751987

Sabol, T. J., and Pianta, R. C. (2012). Recent trends in research on teacher-child relationships. Attach Hum Dev. 14, 213-231. doi: $10.1080 / 14616734.2012 .672262$

\section{AUTHOR CONTRIBUTIONS}

LG wrote a first draft of the editorial text. All co-editors provided revisions on the text. All authors contributed to the article and approved the submitted version.

Sette, S., Gasser, L., and Grütter, J. (2020). Links between teachers' liking of students, peer inclusion, and students' academic achievement: A two-wave longitudinal study. J. Youth Adolesc. 49, 747-756. doi: 10.1007/s10964-019-01048-5

Verschueren, K., and Koomen, H. M. Y. (2012). Teacher-child relationships from an attachment perspective. Attach Hum Dev. 14, 205-211. doi: $10.1080 / 14616734.2012 .672260$

Conflict of Interest: The authors declare that the research was conducted in the absence of any commercial or financial relationships that could be construed as a potential conflict of interest.

Publisher's Note: All claims expressed in this article are solely those of the authors and do not necessarily represent those of their affiliated organizations, or those of the publisher, the editors and the reviewers. Any product that may be evaluated in this article, or claim that may be made by its manufacturer, is not guaranteed or endorsed by the publisher.

Copyright (c) 2022 Gasser, Cillessen, Huber, Mainhard, Müller and Zurbriggen. This is an open-access article distributed under the terms of the Creative Commons Attribution License (CC BY). The use, distribution or reproduction in other forums is permitted, provided the original author(s) and the copyright owner(s) are credited and that the original publication in this journal is cited, in accordance with accepted academic practice. No use, distribution or reproduction is permitted which does not comply with these terms. 